\title{
Temporal trends in the association between socioeconomic status and cancer survival in Ontario: a population-based retrospective study
}

\author{
Andrew Dabbikeh MSc, Yingwei Peng PhD, William J. Mackillop MB ChB, Christopher M. Booth MD, \\ Jina Zhang-Salomons MSc
}

\section{Abstract}

Background: Cancer survival is known to be associated with socioeconomic status. The income gap between the richer and poorer segments of the population has widened over the last 20 years in Canada. The purpose of this study was to investigate temporal trends in disparities in cancer-specific survival related to socioeconomic status in Ontario.

Methods: There were 920334 cancer cases between 1993 and 2009 in the Ontario Cancer Registry. We linked median household income from the Canadian census to the registry. We calculated 5-year cancer-specific survival rates for all cancers combined and for specific cancer sites by socioeconomic status quintile and year of diagnosis, and modelled time to death using Cox regression.

Results: Between 1993 and 2009, for all cancers combined, the hazard of death decreased by 3.1\% (hazard ratio [HR] 0.969 [95\% confidence interval $(\mathrm{Cl}) 0.967-0.971])$ per year in the richest quintile and by $1.2 \%(\mathrm{HR} 0.988$ [95\% $\mathrm{Cl} 0.987-0.990])$ per year in the poorest quintile. The corresponding values for breast cancer were 4.3\% (HR 0.957 [95\% Cl $0.951-0.964])$ and $2.0 \%$ (HR 0.980 [95\% Cl 0.975-0.986]); for lung cancer, 1.4\% (HR 0.986 [95\% Cl 0.982-0.990]) and 0.3\% (HR 0.997 [95\% Cl 0.995-1.000]); for colorectal cancer, 3.7\% (HR 0.963 [95\% Cl 0.958-0.968]) and 1.8\% (HR 0.982 [95\% Cl 0.978-0.985]); and for head and neck cancer, 3.1\% (HR 0.969 [95\% Cl 0.958-0.979]) and 1.0\% (HR 0.990 [95\% Cl 0.983-0.996]).

Interpretation: Between 1993 and 2009, cancer-specific survival in Ontario improved more among patients from affluent communities than among those from poorer communities. This phenomenon cannot be explained by increased disparity in income.

ince the first report of an association between socioeconomic status and cancer survival, by Cohart $^{1}$ in 1955 , it has become well established that socioeconomic status is a predictor of cancer survival., ${ }^{2,3}$ This association has been observed consistently in studies from various health care systems in North America, Australia and Europe. $^{2,3}$ In the late 1990 s and early 2000s, investigators compared the effect of socioeconomic status on cancer survival in Ontario with that observed in the Surveillance, Epidemiology and End Results (SEER) population of the United States. ${ }^{4-6}$ It was shown that, despite Canada's system of universal health insurance, there was a significant association between socioeconomic status and survival for several major types of cancer. ${ }^{4}$ The magnitude of the association was, however, smaller in Ontario than in the US. ${ }^{5}$

Over the last 2 decades, public health agencies in Canada and elsewhere have emphasized the importance of reducing social disparities in health. ${ }^{7,8}$ At the same time, income inequality has been increasing in many countries, including Canada. ${ }^{9}$ It is not known whether these changes in income distribution have translated into an increase in income-related disparities in cancer survival.

Few studies have assessed the temporal trend in the association between socioeconomic status and cancer survival. McDonald and colleagues ${ }^{10}$ investigated this trend for head and neck cancer in Canada from 1992 to 2005 and found a significant increase in the difference in survival between the

Competing interests: None declared.

This article has been peer reviewed.

Correspondence to: Jina Zhang-Salomons, Jina.Zhang-Salomons@ krcc.on.ca

CMAJ Open 2017. DOI:10.9778/cmajo.20170025 
richest and poorest segments of the population for oropharynx cancer, a disease whose cause has shifted from predominantly smoking to human papillomavirus infection. ${ }^{11}$ In a prospective cohort study in the United Kingdom, Ramsay and colleagues $^{12}$ investigated the same time trend by social class, defined by occupation, among 7489 men and observed no change in the association between cancer survival and occupation during their 35-year follow-up period. In the US, Niu and colleagues ${ }^{13}$ examined whether the disparity in cancer survival by insurance status changed between 1999 and 2004 and found that survival improved for privately insured patients but not for those insured by Medicaid. The objective of the current study was to determine whether the magnitude of the association between socioeconomic status and cancer survival changed between 1993 and 2009 in Ontario.

\section{Methods}

\section{Source of data}

This was a population-based retrospective study. We identified cancer cases diagnosed between 1993 and 2009 through the Ontario Cancer Registry, which provides age, sex, postal code at diagnosis, date of diagnosis, disease site, date of death and cause of death. Disease sites are coded with the use of the International Classification of Diseases for Oncology, 3rd edition. Cause of death, provided as International Classification of Diseases, 9th revision and 10th revision codes, is available up to Dec. 31, 2011, and date of death is complete up to Dec. 31, 2013.

We obtained data on gross median household income from the 1996, 2001 and 2006 Canadian censuses (Statistics Canada), at the level of enumeration area for the 1996 and 2001 censuses and dissemination area for the 2006 census. We grouped census dissemination/enumeration areas into quintiles based on median household income, with the fifth quintile (Q5) representing the communities where the wealthiest $20 \%$ of the population resided and the first quintile (Q1) representing the communities where the poorest $20 \%$ resided.

We linked median household income quintile to each cancer case through the patient's postal code by using Statistics Canada's Postal Code Conversion File Plus, ${ }^{14}$ which provides the correspondence between postal code and dissemination/ enumeration area. Although the postal code and dissemination/ enumeration area are similar in size, their boundaries do not correspond. In cases in which the postal code straddled the boundary of more than 1 dissemination/enumeration area, we selected the dissemination/enumeration area with the most dwellings in the postal code. We assigned the median household income from the 1996 census (1995 income), 2001 census (2000 income) and 2006 census (2005 income) to cases diagnosed in 1993-1997, 1998-2002 and 2003-2009, respectively.

\section{Statistical analysis}

We estimated 5-year cancer-specific survival for 1993-2006 (cases with complete follow-up at 5 years after diagnosis) by socioeconomic status and year of diagnosis. Five-year cancerspecific survival was calculated as 1 minus the cumulative inci- dence function for death from any cancer at 5 years from diagnosis. We calculated survival time (in months) from the date of diagnosis to the date of death from cancer, to the date of death from other causes (competing events) or to Dec. 31, 2011 if still alive (censored).

We used Fine-Gray subdistribution proportional hazards regression to investigate the interaction effect between socioeconomic status and year of diagnosis on time to cancer death, controlling for age and sex, and to calculate hazard ratios (HRs). ${ }^{15,16}$ All cases diagnosed between 1993 and 2009 were included in this analysis. The results were considered significant at the 0.05 level, and all tests of statistical significance were two-sided. We performed the statistical analysis using SAS version 9.4 (SAS Institute Inc.).

\section{Ethics approval}

The study obtained ethics approval from Queen's University.

\section{Results}

\section{Study population}

There were 920334 cancer cases during the study period. Table 1 presents summary statistics for the study population. The median age was 67 years; males represented a slightly larger proportion (51.9\%) than females. Fifteen percent of the patients resided in Q5 (richest), and 22.9\% resided in Q1 (poorest). The annual number of incident cases increased over time, from 44165 in 1993 to 65522 in 2009. Breast cancer accounted for the highest proportion of all cancer cases, followed by lung, colorectal, and head and neck cancers. There was no difference in the case-mix between cancer sites across the years (Appendix 1, Supplementary Table 1, available at www.cmajopen.ca/content/5/3/E682/suppl/DC1).

\section{Temporal trend in survival by socioeconomic status quintiles}

Improvement in cancer survival in Ontario between 1993 and 2006 differed by socioeconomic status quintile (Figure 1). For all cancers combined, the 5-year cancer-specific survival rate for patients in Q1 improved by 3.5 percentage points, from $55.3 \%$ (95\% confidence interval [CI] 54.4\%-56.2\%) in 1993 to $58.8 \%(95 \%$ CI $58.0 \%-59.6 \%)$ in 2006 . For patients in Q5, the rate improved by 8.6 percentage points, from $63.4 \%$ (95\% CI $62.1 \%-64.6 \%)$ to $72.0 \%$ (95\% CI $71.1 \%-72.9 \%$ ). The difference in the survival rate between Q1 and Q5 widened from 8.1 percentage points in 1993 to 13.2 percentage points in 2006.

Similar temporal trends were found for specific cancer sites, but at different magnitudes (Figure 2). For breast cancer, the 5-year cancer-specific survival rate for patients in Q1 improved by 2.2 percentage points, from $80.4 \%$ (95\% CI $78.3 \%-82.4 \%$ ) to $82.6 \%$ ( $95 \%$ CI $80.8 \%-84.3 \%$ ), whereas the rate for those in Q5 improved by 5.4 percentage points, from $83.1 \%$ (95\% CI $80.7 \%-85.4 \%)$ to $88.5 \%$ (95\% CI $86.8 \%-90.0 \%)$. The difference between Q1 and Q5 widened from 2.7 percentage points in 1993 to 5.9 percentage points in 2006. For lung cancer, the 5 -year cancer-specific survival rate 


\begin{tabular}{|c|c|}
\hline Variable & $\begin{array}{c}\text { No. }(\%) \text { of cases } \\
n=920334\end{array}$ \\
\hline \multicolumn{2}{|l|}{ Age, yr } \\
\hline$<50$ & $136515(14.8)$ \\
\hline $50-59$ & $154531(16.8)$ \\
\hline $60-69$ & $234047(25.4)$ \\
\hline $70-79$ & $249900(27.2)$ \\
\hline$\geq 80$ & $145341(15.8)$ \\
\hline \multicolumn{2}{|l|}{ Sex } \\
\hline Male & $477336(51.9)$ \\
\hline Female & $442998(48.1)$ \\
\hline \multicolumn{2}{|l|}{ Year } \\
\hline 1993 & $44165(4.8)$ \\
\hline 1994 & $44847(4.9)$ \\
\hline 1995 & $44738(4.9)$ \\
\hline 1996 & $46082(5.0)$ \\
\hline 1997 & $47804(5.2)$ \\
\hline 1998 & $49403(5.4)$ \\
\hline 1999 & $51164(5.6)$ \\
\hline 2000 & $52811(5.7)$ \\
\hline 2001 & $54559(5.9)$ \\
\hline 2002 & $55452(6.0)$ \\
\hline 2003 & $56098(6.1)$ \\
\hline 2004 & $58477(6.4)$ \\
\hline 2005 & $59971(6.5)$ \\
\hline 2006 & $61439(6.7)$ \\
\hline 2007 & $63909(6.9)$ \\
\hline 2008 & $63893(6.9)$ \\
\hline 2009 & $65522(7.1)$ \\
\hline \multicolumn{2}{|c|}{ Socioeconomic status quintile } \\
\hline 1 (poorest) & 210539 (22.9) \\
\hline 2 & $197432(21.4)$ \\
\hline 3 & $180032(19.6)$ \\
\hline 4 & $157701(17.1)$ \\
\hline 5 (richest) & $137659(15.0)$ \\
\hline Missing & $36971(4.0)$ \\
\hline \multicolumn{2}{|l|}{ Site* } \\
\hline Breast & $124221(13.5)$ \\
\hline Lung & $122889(13.4)$ \\
\hline Head and neck & 30695 (3.3) \\
\hline Colorectal & 122183 (13.3) \\
\hline Other & $520346(56.5)$ \\
\hline \multicolumn{2}{|c|}{$\begin{array}{l}\text { *The International Classification of Diseases for Oncology, 3rd edition codes for } \\
\text { the specific cancer sites are: breast C50, lung C } 34 \text {, head and neck C00-C14 } \\
\text { and C } 30-\text { C } 32 \text {, and colorectal C } 18-C 21 \text { and C26.0. All sites include all malignant } \\
\text { cancer cases except nonmelanoma skin cancer. }\end{array}$} \\
\hline
\end{tabular}

for patients in Q1 decreased by 0.3 percentage points, from $21.7 \%$ (95\% CI $20.0 \%-23.6 \%$ ) to $21.4 \%$ (95\% CI $19.7 \%-$ $23.1 \%)$. In contrast, the survival rate for those in Q5 increased by 3.3 percentage points, from $22.0 \%$ (95\% CI $19.0 \%-$ $25.4 \%)$ to $25.3 \%$ (95\% CI $22.6 \%-28.3 \%)$. The difference in the survival rate between Q1 and Q5 widened from 0.3 percentage points in 1993 to 3.9 percentage points in 2006. There was no substantial change in survival over the study period for patients in Q2-Q4. For colorectal cancer, the 5 -year cancer-specific survival rate among patients in Q1 increased by 3.4 percentage points, from $56.2 \%$ (95\% CI $53.8 \%-58.6 \%)$ to $59.6 \%$ (95\% CI $57.3 \%-61.8 \%)$, whereas the rate among those in Q5 increased by 12.3 percentage points, from $56.5 \%$ (95\% CI $52.9 \%-60.2 \%)$ to $68.8 \%(95 \%$ CI 66.2\%-71.4\%). The difference between Q1 and Q5 widened from 0.3 percentage points in 1993 to 9.2 percentage points in 2006. Finally, for cancers of the head and neck, the 5 -year cancer-specific survival rate for patients in Q1 increased by 5.0 percentage points, from $57.6 \%$ (95\% CI $53.1 \%-62.1 \%)$ to $62.6 \%$ (95\% CI $58.2 \%-67.0 \%)$. For those in $\mathrm{Q} 5$, the survival rate increased by 4.9 percentage points, from $69.5 \%(95 \%$ CI $62.4 \%-76.4 \%)$ to $74.4 \%$ (95\% CI $69.1 \%-79.4 \%)$.

Fitting a Fine-Gray model confirmed a significant interaction between socioeconomic status quintile and year of diagnosis after age and sex were controlled for (see Appendix 1, Supplementary Table 2, for $p$ values). During the study period, for all cancers combined, the hazard of death decreased by 3.1\% per year for patients in Q5 and by $1.2 \%$ per year for those in Q1. The corresponding values for breast cancer were $4.3 \%$ and $2.0 \%$; for lung cancer, $1.4 \%$ and $0.3 \%$; for colorectal cancer, $3.7 \%$ and $1.8 \%$; and for head and neck cancer, $3.1 \%$ and $1.0 \%$. HRs and $95 \%$ CIs are shown in column 3 of Table 2.

\section{Temporal trend in survival by median household income}

During the study period, median income in Q1 remained relatively constant, whereas median income in the higherincome quintiles increased substantially (Figure 3). As a result, the gap in median income between Q5 and Q1 widened, from $\$ 56706$ in the 1996 census to $\$ 70693$ (in 2010 constant dollars) in the 2006 census, an increase of $24.7 \%$. Because the analysis treated the quintiles as categorical variables, the effect observed could be in part mediated by the increase in the income gap alone. To obviate this potential mediation effect, we converted median household income at the level of the dissemination/enumeration area from each census into 2010 constant dollars and used this income value to fit a second Fine-Gray model (Appendix 1, Supplementary Table 3). The model revealed significant interactions between year of diagnosis and median household income for the 5 major disease sites and for all cancers combined. The hazard of death per year of diagnosis was lower in the communities with higher median household income and higher in the communities with lower median household income (column 5 of Table 2). For example, when all cancers were combined, the 


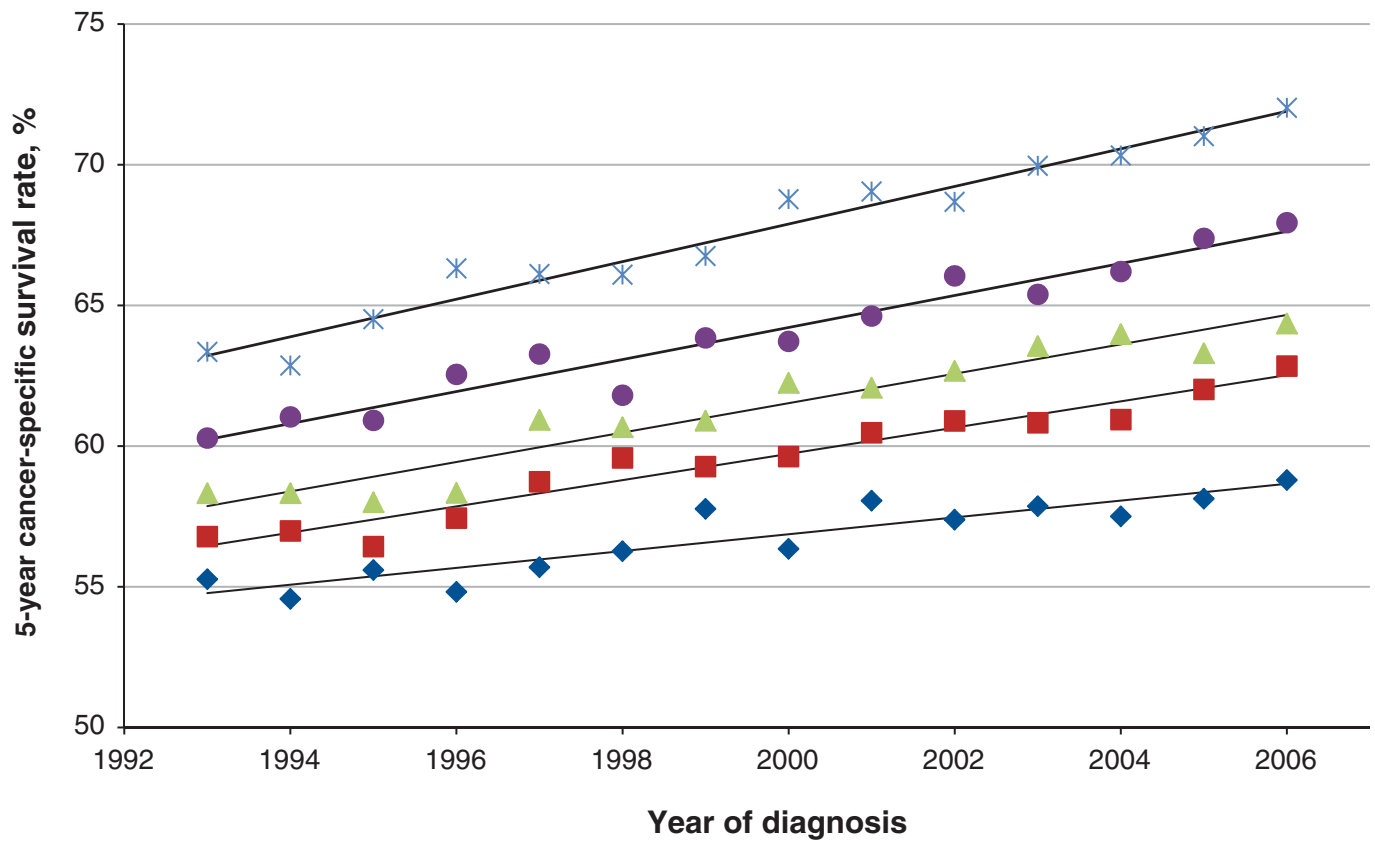

- Quintile 1 Q Quintile $2 \Delta$ Quintile $3 \bullet$ Quintile $4 *$ Quintile 5

Figure 1: Temporal trends in 5-year cancer-specific survival rate for all cancers in Ontario, 1993-2006, by socioeconomic status quintile $(1=$ poorest, 5 = richest $)$.

hazard of death decreased by $0.9 \%$ (HR 0.991 [95\% CI 0.989-0.993]) per year in the communities with a median household income of $\$ 20000$ and decreased by $3.1 \%$ (HR 0.969 [95\% CI 0.966-0.973]) per year in the communities with a median household income of $\$ 100000$. This informs us that, regardless of the actual income range in 1993 and 2006, patients in the communities with the same lower income (e.g., \$20 000) saw a slower improvement in survival than those in the communities with the same higher income (e.g., \$100 000). Therefore, the observed disparity in the survival trend was unrelated to the increased income range over the years.

\section{Interpretation}

We found that, between 1993 and 2006, cancer-specific survival in Ontario improved, but the improvement was greater among patients from affluent communities than among those from poorer communities, and income-associated disparities in survival therefore widened. This phenomenon was observed for cancers of the lung, breast, colon-rectum, and head and neck as well as for all cancers combined. Furthermore, our analysis showed that the income-associated disparities in the survival trend could not be explained simply by the widened disparity in income.

The overall improvements in cancer-specific survival that we observed probably reflect earlier diagnosis owing to improved screening or improvements in treatment or both. The fact that survival improved more among patients residing in richer communities suggests that, in general, improvements in screening and treatment may have had more impact in this group than in those residing in poorer communities. The specific explanations for the widening gap in survival between richer and poorer populations probably differ among the different types of cancer. For example, for breast cancer, for which screening is known to improve outcomes at the population level, ${ }^{17,18}$ differences in the use of screening related to socioeconomic status may contribute to the differences in cancer-specific survival related to socioeconomic status. Consistent with this hypothesis, an Ontario study of breast cancer screening between 1999 and 2010 showed that mammographic screening was used less frequently in lower-income neighbourhoods. ${ }^{19}$ However, those authors did not find an increase in income-associated disparities in screening rates over time. Further study is required to determine whether disparities in the use of screening related to socioeconomic status have increased in recent years for other diseases for which screening is effective. However, differential use of screening does not offer any explanation for the widening gap in survival between richer and poorer populations for lung or head and neck cancer because no screening was routinely offered in Ontario for either of these diseases.

Multiple incremental improvements in the effectiveness of cancer treatment are probably responsible for much of the 

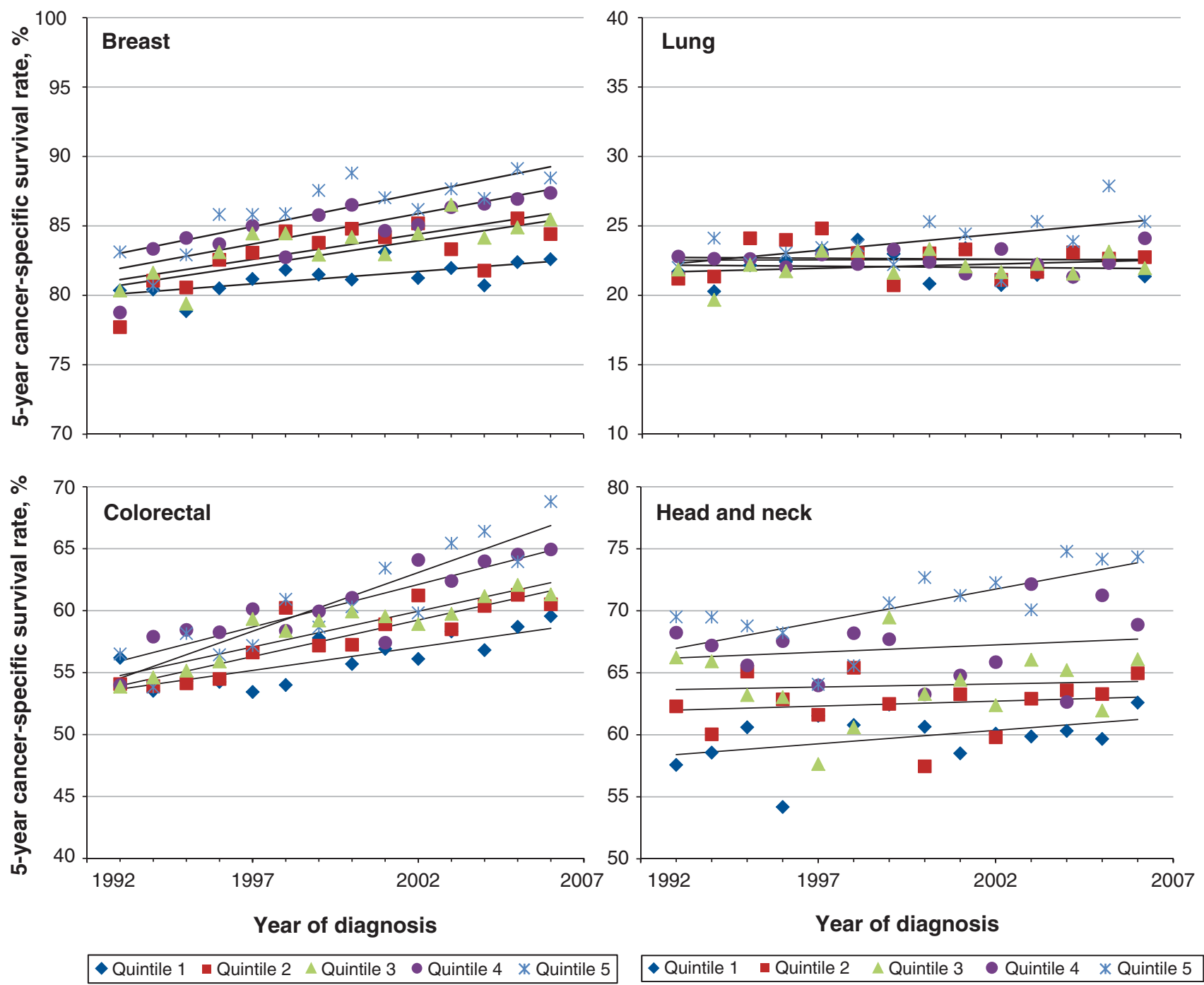

Figure 2: Temporal trends in 5-year cancer-specific survival rates for breast cancer, lung cancer, colorectal cancer, and head and neck cancer in Ontario, 1993-2006, by socioeconomic status quintile ( 1 = poorest, 5 = richest).

overall improvement in cancer-specific survival observed in this study. Over the last 2 decades, new and increasingly effective types of adjuvant treatment have become available for many types of cancer. Furthermore, there is evidence from Ontario that new forms of adjuvant treatment are used more frequently in richer communities. ${ }^{20,21}$ Thus, it seems probable that the more rapid adoption of effective new treatments in richer communities may be responsible for the observed increase in disparity in cancer-specific survival associated with socioeconomic status.

Comorbidity in patients with cancer has been shown to vary by socioeconomic status ${ }^{22,23}$ and has been found to be associated with poorer cancer-specific survival for some diseases, although to a lesser degree than with all-cause survival. ${ }^{24}$ Comorbidity of patients with cancer by socio- economic status in Ontario has not been reported, and therefore it is difficult to ascertain whether the observed time trend in disparity in survival associated with socioeconomic status was related to comorbidity. Lifestyle factors as a mediator between socioeconomic status and survival have also been proposed: Woods and colleagues ${ }^{3}$ suggested that such lifestyle factors as smoking or poor diet could lead to overall poorer health of patients with cancer and therefore reduce their chance of survival. An Ontario study on disparities in tobacco use related to socioeconomic status in the general population showed no interaction between time and education between 1999 and 2006, although both smoking rates and education level increased over time. ${ }^{25}$ Further research is needed on the relation between socioeconomic status, smoking status and cancer 


\begin{tabular}{|c|c|c|c|c|}
\hline Site & $\begin{array}{l}\text { Socioeconomic } \\
\text { status quintile* }\end{array}$ & Hazard ratio $(95 \% \mathrm{Cl})$ & $\begin{array}{c}\text { Gross median } \\
\text { household income, } \\
2010 \text { constant } \\
\text { dollars }\end{array}$ & Hazard ratio $(95 \% \mathrm{Cl})$ \\
\hline \multirow[t]{5}{*}{ All cancers } & 1 (poorest) & $0.988(0.987-0.990)$ & 20000 & $0.991(0.989-0.993)$ \\
\hline & 2 & $0.983(0.982-0.985)$ & 40000 & $0.985(0.983-0.988)$ \\
\hline & 3 & $0.980(0.978-0.981)$ & 60000 & $0.980(0.977-0.983)$ \\
\hline & 4 & $0.977(0.975-0.979)$ & 80000 & $0.975(0.971-0.978)$ \\
\hline & 5 (richest) & $0.969(0.967-0.971)$ & 100000 & $0.969(0.966-0.973)$ \\
\hline \multirow[t]{5}{*}{ Breast } & 1 & $0.980(0.975-0.986)$ & 20000 & $0.985(0.981-0.988)$ \\
\hline & 2 & $0.974(0.968-0.976)$ & 40000 & $0.979(0.975-0.983)$ \\
\hline & 3 & $0.968(0.962-0.973)$ & 60000 & $0.974(0.970-0.978)$ \\
\hline & 4 & $0.966(0.960-0.972)$ & 80000 & $0.968(0.964-0.973)$ \\
\hline & 5 & $0.957(0.951-0.964)$ & 100000 & $0.963(0.958-0.968)$ \\
\hline \multirow[t]{5}{*}{ Lung } & 1 & $0.997(0.995-1.000)$ & 20000 & $0.997(0.995-0.999)$ \\
\hline & 2 & $0.997(0.995-1.000)$ & 40000 & $0.992(0.989-0.994)$ \\
\hline & 3 & $0.995(0.992-0.997)$ & 60000 & $0.986(0.983-0.989)$ \\
\hline & 4 & $0.996(0.992-0.997)$ & 80000 & $0.981(0.977-0.984)$ \\
\hline & 5 & $0.986(0.982-0.990)$ & 100000 & $0.975(0.971-0.979)$ \\
\hline \multirow[t]{5}{*}{ Colon-rectum } & 1 & $0.982(0.978-0.985)$ & 20000 & $0.987(0.984-0.989)$ \\
\hline & 2 & $0.978(0.975-0.982)$ & 40000 & $0.981(0.978-0.984)$ \\
\hline & 3 & $0.975(0.971-0.979)$ & 60000 & $0.976(0.972-0.979)$ \\
\hline & 4 & $0.971(0.966-0.975)$ & 80000 & $0.970(0.967-0.974)$ \\
\hline & 5 & $0.963(0.958-0.968)$ & 100000 & $0.965(0.961-0.969)$ \\
\hline \multirow[t]{5}{*}{ Head and neck } & 1 & $0.990(0.983-0.996)$ & 20000 & $0.996(0.991-1.000)$ \\
\hline & 2 & $0.988(0.981-0.995)$ & 40000 & $0.990(0.985-0.995)$ \\
\hline & 3 & $0.985(0.978-0.993)$ & 60000 & $0.985(0.979-0.990)$ \\
\hline & 4 & $0.979(0.970-0.988)$ & 80000 & $0.979(0.974-0.984)$ \\
\hline & 5 & 0.969 (0.958-0.979) & 100000 & $0.974(0.968-0.979)$ \\
\hline
\end{tabular}

survival to better understand the temporal trend observed in the current study.

The temporal trend in disparity in cancer survival associated with socioeconomic status that we observed has important implications for the management of cancer care. The overall improved cancer survival is consistent with improved access to diagnosis and treatments. ${ }^{26}$ However, the lesser improvement in outcomes observed in poorer populations suggests that new approaches to cancer diagnosis and treatment may be adopted more slowly among groups of lower socioeconomic status. Further study focusing on particular disease groups is required to identify the specific factors that mediate the association between socioeconomic status and survival. A better understanding of the causal pathway between socioeconomic status and cancer survival is needed to inform strategies aimed at narrowing the gap in survival between richer and poorer populations. Similar studies in various countries with different social and health care systems may also help further our understanding of this important determinant of health.

\section{Limitations}

The accuracy of classification of cause of death is a known concern for calculating cancer-specific survival. Hall and colleagues ${ }^{27}$ compared classification of cause of death in the Ontario Cancer Registry with that recorded in a clinical database for a group of patients with squamous carcinoma of the head and neck. Among the 276 patients who died 


\section{OPEN}

Research

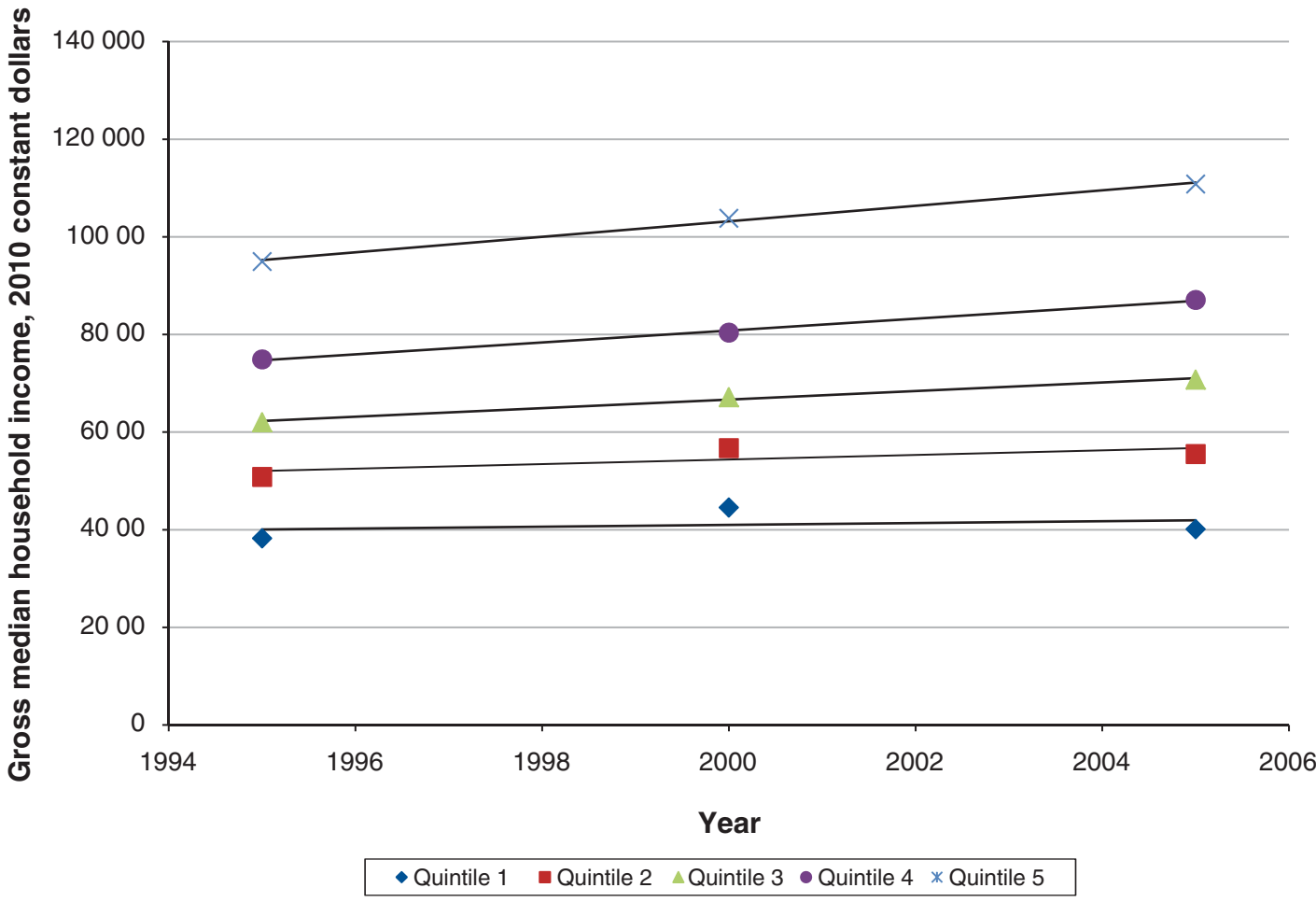

Figure 3: Gross median household income in 2010 constant dollars for income quintiles 1-5 from the 1996, 2001 and 2006 censuses.

from head and neck cancer, death was misclassified as noncancer death for 23 (8.3\%). Misclassification from death from other causes to death from head and neck cancer also occurred. Furthermore, the authors found no difference in cancer-specific survival calculated using the Ontario Cancer Registry and that calculated using their clinical database, which could be explained if the pattern of misclassification were random. Although misclassification of cause of death does occur, there is no evidence to suggest that misclassification was responsible for the increased disparity in cancer-specific survival related to socioeconomic status observed in the current study. In addition, the measure of socioeconomic status that we used was community-level socioeconomic status and cannot be interpreted as the socioeconomic status of individual patients. Nonetheless, a previous study incorporating both community-level and individual-level socioeconomic status in a multilevel analysis showed independent effects of the 2 measures on breast cancer incidence and therefore suggested that communitylevel socioeconomic status may capture an unmeasured aspect of individual socioeconomic status. ${ }^{28}$

\section{Conclusion}

Despite increased awareness of the relation between socioeconomic status and cancer survival, between 1993 and 2009, cancer-specific survival in Ontario improved less among patients from poor communities than among those from afflu- ent communities, and this phenomenon cannot be explained by increased disparity in income. The causes of the disparity need to be identified so that targeted interventions can be designed to address this issue.

\section{References}

1. Cohart EM. Socioeconomic distribution of cancer of the female sex organs in New Haven. Cancer 1955;8:34-41.

2. Kogevinas $M$, Porta $M$. Socioeconomic differences in cancer survival: a review of the evidence. IARC Sci Publ 1997;138:177-206.

3. Woods LM, Rachet B, Coleman MP. Origins of socio-economic inequalities in cancer survival: a review. Ann Oncol 2006;17:5-19.

4. Mackillop WJ, Zhang-Salomons J, Groome PA, et al. Socioeconomic status and cancer survival in Ontario. 7 Clin Oncol 1997;15:1680-9.

5. Boyd C, Zhang-Salomons J, Groome PA, et al. Associations between community income and cancer survival in Ontario, Canada, and the United States. $f$ Clin Oncol 1999;17:2244-55.

6. Zhang-Salomons J, Qian H, Holowaty E, et al. Associations between socioeconomic status and cancer survival: choice of SES indicator may affect results. Ann Epidemiol 2006;16:521-8.

7. Ontario Cancer Plan IV 2015-2019. Toronto: Cancer Care Ontario; 2014. Available: https://cancercare.on.ca/common/pages/UserFile.aspx? fileId $=333871$ (accessed 2015 Nov. 13).

8. Closing the gap in a generation: bealth equity through action on the social determinants of health. Final report of the Commission on Social Determinants of Health. Geneva: World Health Organization; 2008. Available: www.who.int/social_ determinants/thecommission/finalreport/en/ (accessed 2015 Nov. 13).

9. Income inequity. Ottawa: Conference Board of Canada; 2013. Available: www. conferenceboard.ca/hcp/details/society/income-inequality.aspx (accessed 2015 Nov. 13).

10. McDonald JT, Johnson-Obaseki S, Hwang E, et al. The relationship between survival and socio-economic status for head and neck cancer in Canada. $f$ Otolaryngol Head Neck Surg 2014;43:2-8.

11. Gupta S, Kong W, Peng Y, et al. Temporal trends in the incidence and survival of cancers of the upper aerodigestive tract in Ontario and the United States. Int 7 Cancer 2009; 125:2159-65. 
12. Ramsay SE, Morris RW, Whincup PH, et al. Time trends in socioeconomic inequalities in cancer mortality: results from a 35 year prospective study in British men. BMC Cancer 2014;14:474.

13. Niu X, Roche LM, Pawlish KS, et al. Cancer survival disparities by health insurance status. Cancer Med 2013;2:403-11.

14. Postal Code Conversion File (PCCF). Cat no 92-153-XCB. Ottawa: Geography Division, Statistics Canada; 2011

15. Fine JP, Gray RJ. A proportional hazards model for the subdistribution of a competing risk. 7 Am Stat Assoc 1999;94:496-509.

16. Geskus RB. Cause-specific cumulative incidence estimation and the Fine and Gray model under both left truncation and right censoring. Biometrics 2011;67:39-49.

17. Schopper D, de Wolf C. How effective are breast cancer screening programmes by mammography? Review of the current evidence. Eur 7 Cancer 2009;45:1916-23

18. Coldman A, Phillips N, Warren L, et al. Breast cancer mortality after screening mammography in British Columbia women. Int 7 Cancer 2007;120:1076-80.

19. Kiran T, Wilton AS, Moineddin R, et al. Effect of payment incentives on cancer screening in Ontario primary care. Ann Fam Med 2014;12:317-23.

20. Booth CM, Nanhji S, Wei X, et al. Use and effectiveness of adjuvant chemotherapy for stage III colon cancer: a population-based study. 7 Natl Compr Canc Netw 2016;14:47-56.

21. Booth CM, Siemens DR, Li G, et al. Perioperative chemotherapy for muscleinvasive bladder cancer: a population-based outcomes study. Cancer 2014;120: 1630-8.

22. Schrijvers CT, Coebergh JW, Mackenbach JP. Socioeconomic status and comorbidity among newly diagnosed cancer patients. Cancer 1997;80:1482-8.

23. Grose D, Morrison DS, Devereux G, et al.; Scottish Lung Cancer Forum. Comorbidities in lung cancer: prevalence, severity and links with socioeconomic status and treatment. Postgrad Med 7 2014;90:305-10.

24. Søgaard M, Thomsen RW, Bossen KS, et al. The impact of comorbidity on cancer survival: a review. Clin Epidemiol 2013;5(Suppl 1):3-29.

25. Reid JL, Hammond D, Driezen P. Socio-economic status and smoking in Canada, 1999-2006: Has there been any progress on disparities in tobacco use? Can 7 Public Health 2010;101:73-8.

26. Cancer System Quality Index (CSQI) 2016. Toronto: Cancer Quality Council of Ontario; 2016. Available: www.csqi.on.ca (accessed 2017 May 10).
27. Hall S, Schulze K, Groome P, et al. Using cancer registry data for survival studies: the example of the Ontario Cancer Registry. 7 Clin Epidemiol 2006:59:67-76.

28. Webster TF, Hoffman K, Weinberg J, et al. Community- and individual-level socioeconomic status and breast cancer risk: multilevel modeling on Cape Cod, Massachusetts. Environ Health Perspect 2008;116:1125-9.

Affiliations: Departments of Public Health Sciences (Dabbikeh, Peng, Mackillop, Zhang-Salomons) and Oncology (Mackillop, Booth, ZhangSalomons); Division of Cancer Care and Epidemiology (Peng, Mackillop, Booth, Zhang-Salomons), Cancer Research Institute, Queen's University, Kingston, Ont.

Contributors: Jina Zhang-Salomons conceived the study, supervised and reviewed the data linkage, analysis and results, and revised the manuscript for important intellectual content. William Mackillop and Christopher Booth contributed to the study conception and the interpretation of the data, and revised the manuscript for important intellectual content. Andrew Dabbikeh linked the socioeconomic status data, conducted the data analysis, prepared the tables and figures, and drafted the manuscript. Yingwei Peng was responsible for the statistical methodology, reviewed the results and revised the manuscript for important intellectual content. All of the authors approved the final version to be published and agreed to act as guarantors of the work.

Funding: This research was funded by Cancer Care Ontario.

Acknowledgements: The authors thank Cancer Care Ontario for providing the data. Thanks also go to Patti Groome, Michael Brundage, Keyue Ding and Michael McIssac for their helpful comments on the study.

Supplemental information: For reviewer comments and the original submission of this manuscript, please see www.cmajopen.ca/content $/ 5 / 3$ / E682/suppl/DC1. 